\title{
Cost-effectiveness analysis of caplacizumab in the new standard of care of immune thrombotic thrombocytopenic purpura in Italy
}

\author{
Giovanni Di Minnoํㅜ, Roberto Ravasio² \\ ${ }^{1}$ Regional Reference Center for Coagulation Disorders, Federico II University Hospital, Naples - Italy \\ ${ }^{2}$ HEOR and RWE Lead, Market Access Provider, Milan - Italy
}

\begin{abstract}
Objectives: To evaluate the cost-effectiveness analysis (CEA) of caplacizumab in combination with plasmapheresis (plasma exchange, PEX) and immunosuppression compared to PEX and immunosuppression in the treatment of acute episodes of immune thrombotic thrombocytopenic purpura (iTTP).

Methods: A Markov model was used to conduct the CEA from the perspective of the hospital, over a lifetime horizon. Clinical data were derived from HERCULES trial and a systematic literature review. Economic input included direct costs only. Utility and disutility values were obtained from literature. Data on healthcare resources and costs were retrieved from HERCULES trial, literature, TTP guidelines and Italian tariffs. A sensitivity analysis was conducted. The cost-effectiveness probability was tested for several options of discount levels considering a suggested willingness to pay (WTP) threshold of $€ 60,000$ in Italy.

Results: The use of caplacizumab in combination with PEX and immunosuppression is associated with a positive difference in survival of 3.27 life years (24.53 vs. 21.26) and in quality of life of 3.06 quality-adjusted life years (QALY; 22.01 vs. 18.96) when compared to PEX and immunosuppression. Caplacizumab leads to an incremental cost-effectiveness ratio (ICER) per life year of $€ 41,653$ and an ICER per QALY of $€ 44,572$. For the suggested WTP threshold, the probability of caplacizumab being cost-effective is $82.4 \%$ (no discount), $92.8 \%$ (15\% discount), 95.3\% (20\% discount), $96.9 \%$ ( $25 \%$ discount) and $98.2 \%$ (30\% discount).

Conclusions: Caplacizumab in addition to PEX and immunosuppression is cost-effective, allowing the hospital to achieve greater efficiency in managing the burden of a life-threatening disease such as iTTP.

Keywords: Caplacizumab, Cost-effectiveness, Hospital, Immune thrombotic thrombocytopenic purpura, Orphan drug, Rare blood disorders
\end{abstract}

\section{Introduction}

Immune thrombotic thrombocytopenic purpura (iTTP), also called autoimmune thrombocytopaenia, is a thrombotic microangiopathy characterised by a low incidence (2-6/1,000,000 inhabitants) and an average age of about 40 years with a greater female prevalence (over $70 \%)(1,2)$.

The diagnosis of ITTP is essential as, if not treated, it results in a mortality rate of $90 \%$; for this reason, the

Received: October 17, 2020

Accepted: March 6, 2021

Published online: April 2, 2021

Corresponding author:

Roberto Ravasio

Market Access Provider Srl

Via Vincenzo Monti 3

20123 Milan - Italy

ravasio@maprovider.com diagnosis of ITTP should always be treated as a medical emergency.

iTTP is the most common form of thrombotic thrombocytopenic purpura (95\% of cases) (3) and is characterised by antibodies, typically IgG, against the enzyme ADAMTS13 (the 13th member of a disintegrin and metalloproteinase with thrombospondin motifs 13), responsible for the von Willebrand factor (VWF) degradation process in its 'ultralarge' (ULVWF) form $(4,5)$. The enzyme deficiency resulting from this results in the formation of large, potentially occlusive thrombi at the terminal arterioles and capillaries of different organs (heart, pancreas, kidneys, adrenal glands, brain, spleen and liver) (6). All of this can cause anaemia, thrombocytopaenia, tissue ischaemia (kidneys, liver, heart and others), organ dysfunction and acute ischaemic events that can lead to major thromboembolic events and/or premature death (7-13).

An Italian study showed that, in patients with ITTP, the presence of neurological disorders persists even years after the acute phase (14). During the remission phase, the study 
showed significant damage in memory domains compared to the general population (14). In addition to neurological and cognitive problems, the study also detected anxiety and depression (14). A further study showed the negative effect of iTTP on Health-Related Quality of Life (HR-QoL) (15).

Although plasmapheresis (plasma exchange, PEX) and immunosuppression have improved the clinical outcomes of patients with iTTP, the probability of irreversible organ damage and mortality remains significant $(20 \%$, with a median time to death of 9 days [range 4-14 days]) (13). According to data from the English registry, approximately half of deaths occur in the first 24 hours (especially in women) (16). In addition, subjects may experience, in $30 \%-50 \%$ of cases, an exacerbation of the disease (platelet count $<150,000 / \mathrm{mm}^{3}$ for three consecutive days, if a new acute thrombotic episode occurs in the first 30 days after the end of PEX) (13).

Caplacizumab is a bivalent humanised nanobody of $28 \mathrm{kD}$, consisting of two identical humanised structural elements (PMP12A2hum1), linked together by a linker consisting of a triplet of alanine. Caplacizumab acts against the A1 domain of vWF, inhibiting the interaction between the latter and platelets (13).

The efficacy and safety of caplacizumab have been investigated due to a clinical trial programme that included the phase III, randomised, double-blind, placebo-controlled, multicentre HERCULES registration study (17). Compared to those treated with PEX and immunosuppression, patients who received caplacizumab in combination with PEX and immunosuppression achieved a faster resolution of the acute episode of iTTP (17). Specifically, $95 \%$ of patients in the group treated with caplacizumab recorded a normalisation of platelet count $\left(\geq 150,000 / \mathrm{mm}^{3}\right)$ on the fifth day of treatment (primary endpoint of the study), compared to $77 \%$ of patients treated with PEX and immunosuppression (17). In addition to the lesser time required to normalise the platelet count, the probability of death following an acute episode of iTTP was significantly reduced and exacerbations and the possibility of a severe thromboembolic event decreased (17-19). Caplacizumab prevents refractory treatment by protecting vital organs from vascular damage, as demonstrated by a faster normalisation of the indicators of such damage (17-19). Caplacizumab reduces the volume $(21.3 \pm 1.6$ vs. $35.9 \pm 4.2$, equal to a $41 \%$ reduction) and the duration (5.8 \pm 0.5 vs. $9.4 \pm 0.8$, equal to a $38 \%$ reduction in plasmapheresis) and the number of days spent in intensive care $(3.4 \pm 0.4$ vs. $9.7 \pm 2.1$, equal to a $65 \%$ reduction) or in ordinary hospitalisation ( $9.9 \pm 0.7$ vs. $14.4 \pm 1.2$, equal to a $31 \%$ reduction) compared to therapy with PEX and immunosuppression alone, with a clear saving of healthcare resources and a reduction in the risk of overexposure to infections (17-19).

Caplacizumab, by virtue of the efficacy data and a favourable safety profile (which allows its use during the entire phase of disease activity and suggests its use as early as possible during disease episodes) (17-19), has been included by AIFA (Agenzia Italiana del Farmaco [Italian Medicines Agency]) in the list of innovative drugs that must be made immediately available to clients, even without formal inclusion in regional hospital treatment manuals (they have not been, furthermore, neither registry nor web-based therapeutic plan) (20).
In light of the greater efficacy shown by the results of the HERCULES study (17) and the constant need of decisionmakers to estimate the value of new therapies, this analysis was conducted with the aim of determining, from the hospital's perspective, the Incremental Cost-Effectiveness Ratio (ICER) of caplacizumab in combination with PEX and immunosuppression, compared to PEX and immunosuppression in the treatment of acute episodes of iTTP.

\section{Methods}

\section{Introduction}

To conduct the Cost-Effectiveness Analysis (CEA) an ad hoc Markov model was developed, able to simulate the clinical course of a patient with an acute episode of iTTP. This type of model is adopted if, for the purposes of the analysis, it is necessary to represent a succession of health states and if each of them can manifest again over time (21). As with each decision-making model, the Markov model, in addition to integrating the data from the reference clinical study with those from other sources (e.g. epidemiological analyses and/ or economic analyses), makes it possible to extend the observation period beyond that (usually short) covered by the clinical study (21). It therefore has the function of replicating the possible paths that can be followed after a certain index event, over a period of time (e.g. 1 year, 5 years or lifetime), divided into units of time called 'cycles', of the duration, for example, of a quarter or 1 year (21). With the beginning of each cycle, there may be a transition of the patient to a different state of health, or the patient may remain in the same state of health (21).

The CEA has made it possible to compare the clinical consequences (simple survival, Life Years [LY], or weighted for the quality of life (QoL), Quality-Adjusted Life Years [QALY]) and economic consequences (direct healthcare costs) of caplacizumab in combination with PEX and immunosuppression compared to PEX and immunosuppression in the treatment of acute episodes of iTTP. The adoption of the CEA is considered adequate when it is assumed that a new healthcare technology may have a positive impact on the survival and/ or QoL of patients compared to the available alternatives. The CEA was conducted from the hospital's perspective. Only direct healthcare costs were considered, such as acquisition of comparator therapies, management of the acute episode of ITTP, management of adverse events associated with the acute episode of iTTP and remission. The CEA results are presented in terms of incremental cost per year of life (LY) gained and incremental cost per year of life corrected for the quality (QALY) gained. Finally, in accordance with the recommendations of the Italian Health Economics Association (Associazione Italiana di Economia Sanitaria [AIES]), costs and benefits that occur beyond the year were discounted by applying a discount of $3.0 \%(22)$. The costs were valued with reference to the year 2020 .

\section{Structure of the Markov model}

The patient enters the model following diagnosis of confirmed iTTP based on ADAMTS13 levels $<10 \%$, with the 
presence of antibodies against ADAMSTS13. Please note that, although the treatment of an episode of iTTP should not be delayed, the ADAMTS13 test results are important to continue the treatment started. The logical-formal structure of the Markov model provides for a first acute phase and a subsequent remission phase, each characterised by four mutually exclusive health states that allow to describe the natural course of the disease and its main implications (Fig. 1). The eight health conditions present in the model are:

- (acute phase) without neurological or cardiac condition (NoNC);

- (acute phase) with acute myocardial infarction event (aMI);

- (acute phase) with acute stroke event (aStroke);

- (acute phase) death due to iTTP;

- (remission phase) without neurological or cardiac condition (NoNC);

- (remission phase) chronic condition post myocardial infarction (cMI);

- (remission phase) chronic post-stroke (cStroke) condition;

- (remission phase) death related or not to iTTP.

The model follows the patient treated over time with caplacizumab combined with PEX and immunosuppression or with PEX and immunosuppression. An average age of onset of the acute episode of ITTP was considered to be 37 years (23) and a female prevalence of $69 \%$ (17). The patient, free from previous chronic conditions, enters the model (acute phase) following hospitalisation for an acute episode of iTTP (index event). In this acute phase (first cycle), the patient, due to the episode, may experience absence (NoNC) or presence of a cardiac (infarction, aMI) or neurological (stroke, aStroke) event or death (Fig. 1). In the subsequent remission phase, the patient passes into the corresponding four remission health states following absence (NoNC) or presence of a cardiac (cMI) or neurological (cStroke) event (Fig. 1). In the remission phase, the patient may meet death due to causes related or not related to the acute episode of iTTP (Fig. 1).

With the objective of identifying the most important differences expressed in terms of both clinical outcome and treatment costs for the two therapeutic options, a timeframe lifetime (24), characterised by 90 -day (3-month) cycles, was considered sufficient to capture the acute episode of iTTP and its natural course (17).

The differentiation between acute (aMI, aStroke) and chronic (cMI, cStroke) states allows the model to forecast the long-term consequences of acute episodes of iTTP, that is, the whether the presence of an acute event such as aMI or aStroke may affect mortality in the remission phase. Finally, the model included other acute events that may occur during the treatment of the acute episode of ITTP, such as complications during plasmapheresis, severe treatment-related bleeding, pulmonary embolism and deep vein thrombosis.

Finally, it was assumed that there is no difference in the results for a patient, if characterised by a previous episode of iTTP.

\section{Clinical data}

The decision-making model was populated using data of efficacy, mortality and morbidity (myocardial infarction, stroke and exacerbation), of complications (pulmonary embolism and deep vein thrombosis), of adverse events (infections during plasmapheresis and severe treatmentrelated bleeding) and of healthcare consumption associated with the two treatment options collected by the HERCULES study (17) and a systematic literature review (25).

In the HERCULES study, 145 patients with a diagnosis of ITTP were enrolled, 72 of whom were treated with caplacizumab in combination with PEX and immunosuppression and 73 with placebo in combination with PEX and immunosuppression. The clinical characteristics of the two groups were well balanced at enrolment. The primary endpoint of the study was the time to platelet count normalisation, defined as the time span from the first intravenous administration of caplacizumab or placebo to platelet count normalisation (i.e. a platelet count at least $>150,000 \mathrm{~mm}^{3}$ ), followed by discontinuation of plasmapheresis within the next 5 days; $95 \%$ of patients in the caplacizumab group had platelet count normalisation $\left(\geq 150,000 / \mathrm{mm}^{3}\right)$ on the fifth day of treatment compared with $77 \%$ of patients treated with placebo in combination with PEX and immunosuppression (hazard ratio 1.55, 95\% confidence interval [Cl]: 1.09-2.19; $\mathrm{p}=0.01$ ).

The time to platelet count normalisation was analysed using a parametric regression model of Weibull (26), whose main parameters are reported in Table I. The systematic

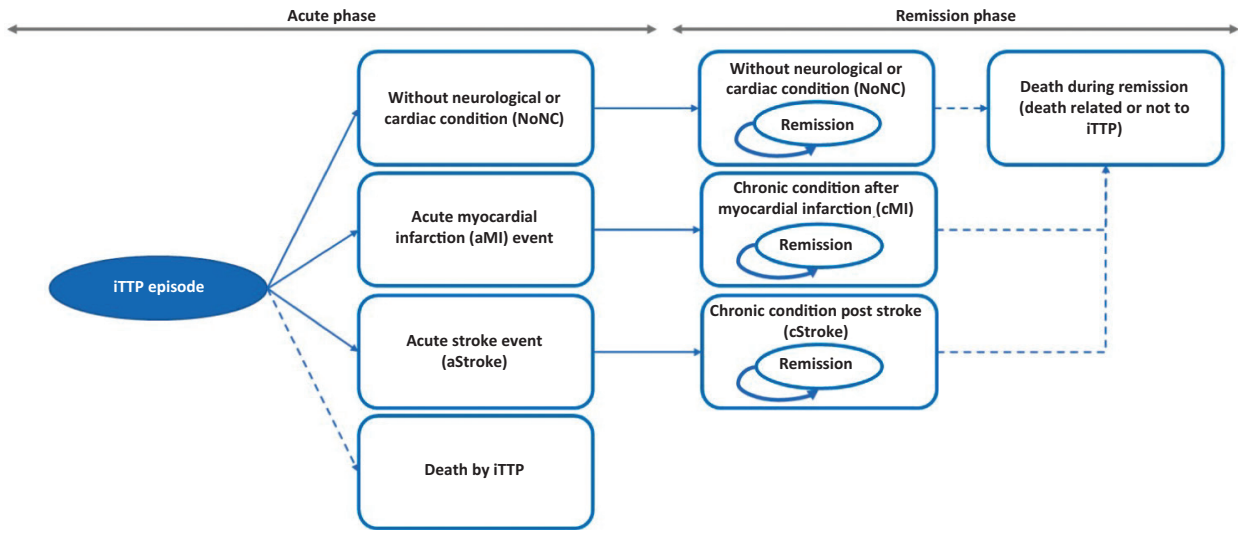

Fig. 1 - Structure of the decisionmaking model. 
TABLE I - Parameters of the Weibull parametric regression model applied to the time to normalisation of the platelet count

\begin{tabular}{lcc}
\hline Time to $\begin{array}{l}\text { Timatel count } \\
\text { normalisation }\end{array}$ & \multicolumn{2}{c}{ Responder to treatment } \\
\cline { 2 - 3 } & $\begin{array}{c}\text { PEX and } \\
\text { immunosuppression }\end{array}$ & $\begin{array}{c}\text { Caplacizumab + PEX and } \\
\text { immunosuppression }\end{array}$ \\
\hline Weibull parameterisation & \\
Shape & 1.56 & $1.56-0.27$ \\
Scale & 0.68 & 0.68 \\
\hline
\end{tabular}

review of the literature (25) included 141 studies for a total of 20,131 patients with at least one episode of iTTP. The main data show that the most important manifestation of an acute episode of both cardiac or neurological iTTP, with high probability, can lead to death or generate a negative impact on the patients' QoL. Table II shows the main efficacy data considered in the model.

\section{Mortality}

Different mortality probabilities were considered in the model.

The first series, based on the HERCULES study and the literature review $(17,25)$, reflects the probability that, during the acute phase, depending on the therapy administered, the patient may die due to the episode of iTTP (Tab. II). In the model, it was hypothesised that, with reference to both cohorts, in the acute phase, the manifestation of an event such as infarction or stroke does not lead to the intra-hospital death of the patient. The second series, on the other hand, reflects the probability that a patient, during the remission phase, may die due to causes unrelated to the acute episode of iTTP. In the latter case, annual mortality due to causes unrelated to the acute episode of ITTP was derived from mortality tables of the general Italian population (ISTAT 2017) (27). Compared to the patient without a chronic neurological or cardiac condition, for the patient with a chronic post-infarction or post-stroke condition (remission phase), an additional risk of mortality was considered (Tab. III) $(28,29)$.

TABLE III - Standardised annual mortality for patients with stroke or myocardial infarction

\begin{tabular}{lcc}
\hline Population & $\begin{array}{c}\text { Annual } \\
\text { mortality }\end{array}$ & Source \\
\hline $\begin{array}{lcc}\text { Patients in chronic condition post-chronic } \\
\text { myocardial infarction* }\end{array}$ & $2.02 \%$ & $(28)$ \\
Patients with acute myocardial infarction* & $2.02 \%$ & $(28)$ \\
Patients in chronic post-stroke condition & $3.90 \%$ & $(29)$ \\
Patients with acute stroke & $3.90 \%$ & (29) \\
\hline
\end{tabular}

* In the absence of specific data for myocardial infarction, the data referring to chronic heart failure (28) were considered as a proxy.

\section{Probability of transition}

Table IV shows the details of the transition probabilities associated with health states related to the acute episode of ITTP for the two treatment groups. These probabilities were determined based on efficacy data from the HERCULES study (17) and the literature review (25). For the purposes of the probabilistic analysis for the NoNC and death health states,

TABLE II - Summary of the data on efficacy, mortality and manifestation of other events during an acute episode of iTTP

\begin{tabular}{|c|c|c|c|c|c|}
\hline Efficacy parameter & $\begin{array}{c}\text { PEX and } \\
\text { immuno- } \\
\text { suppression }\end{array}$ & Source & $\begin{array}{l}\text { Relative } \\
\text { Risk (RR) }\end{array}$ & $\begin{array}{l}\text { Caplacizumab + } \\
\text { PEX and immuno- } \\
\text { suppression }\end{array}$ & Source \\
\hline
\end{tabular}

\section{Clinical response criterion}

$\%$ of patients with exacerbation* after acute episode of iTTP

$36.30 \%$

$4.44 \%$

(25)

0.12

$4.23 \%$

Probability of non-fatal stroke during an acute episode of iTTP

$4.39 \%$

(25)

0.69

$3.06 \% * *$

Probability of non-fatal myocardial infarction during an acute episode of iTTP

\section{Mortality}

Probability of death during an acute episode of iTTP

$13.20 \%$

(25)

0.00

$0.0 \% * *$

\section{Other events during an acute episode of ITTP}

Probability of pulmonary embolism

$0,00 \%$

1.03

$4.52 \% * *$

Probability of deep vein thrombosis

4,11

Rate of infections per patient during plasmapheresis

1,31

$0,00 \%$

$\begin{array}{cl}\text { NA } & 1.41 \% \\ 1,03 & 4.23 \% \\ 0,44 & 0.57 \\ \text { NA } & 0.13\end{array}$

*Exacerbation is defined as a reduction in platelet count $\left(<150,000 / \mathrm{mm}^{3}\right)$ for 3 consecutive days, if a new acute thrombotic episode occurs in the first 30 days after the end of plasmapheresis.

**The data corresponding to caplacizumab in combination with PEX and immunosuppression were calculated by applying the estimated RR in the HERCULES study (16) to the data reported in the table for PEX and immunosuppression. 
TABLE IV - Probability of transition associated with state of health in the acute phase

\begin{tabular}{|c|c|c|c|c|}
\hline Treatment & NoNC & aStroke & aMI & Death \\
\hline PEX and immunosuppression & $79.10 \%$ & $3.90 \%$ & $3.80 \%$ & $13.20 \%$ \\
\hline $\begin{array}{l}\text { Caplacizumab + PEX and } \\
\text { immunosuppression }\end{array}$ & $93.40 \%$ & $2.70 \%$ & $3.90 \%$ & $0.00 \%$ \\
\hline
\end{tabular}

Beta distribution was considered, while, for aStroke and aMI, the lognormal distribution was considered.

\section{Utility}

The QoL of patients was evaluated by attributing specific utility or disutility values for each state of health (Tab. V).

Each patient who enters the model, applying the estimated values for the general Italian population (calculated with the EQ-5D questionnaire) (30), was associated with a utility of 0.939 before the onset of the acute episode of ITTP. Since the HERCULES study (17) did not collect data on the QoL of treated patients and, in the literature, there are no studies that have estimated utility values for patients with an acute episode of iTTP, the model assumed that sickle cell anaemia represents a disease similar to iTTP in terms of impact on QoL, as it is also characterised by frequent hospitalisations in the acute phase.

According to an international study, the utility value for a hospitalised patient with an acute episode of sickle cell disease - measured by the EQ-5D questionnaire is 0.520 (31). The study also reported the mean utility value of 0.750 for the patient in the week following hospital discharge (31). Based on these data, in this model it was assumed that the

TABLE V - Utility values

\begin{tabular}{lcc}
\hline Event & $\begin{array}{c}\text { Utility/disutility } \\
\text { value }\end{array}$ & Source \\
\hline $\begin{array}{l}\text { Baseline - before onset of acute } \\
\text { episode of iTTP }\end{array}$ & 0.939 & $(30)$ \\
Acute episode of iTTP & -0.230 & $(31)$ \\
Exacerbation & -0.230 & Intake \\
Non-fatal infarction - acute phase & 0.786 & $(32)$ \\
Stroke- acute phase & 0.628 & $(32)$ \\
Non-fatal infarction - remission phase & 0.880 & $(32)$ \\
Stroke - remission phase & 0.628 & $(32)$ \\
\hline Complications & -0.250 & $(33)$ \\
Pulmonary embolism & -0.250 & $(33)$ \\
Deep vein thrombosis & & \\
\hline Adverse events & -0.050 & $(25)$ \\
Infections during plasmapheresis & -0.100 & $(25,33,34)$ \\
\hline Treatment-related severe bleeding & & \\
\hline
\end{tabular}

difference of the two values listed above, equal to 0.230 $(0.750-0.520)$, corresponds to the disutility value associated with an acute episode of iTTP or a subsequent exacerbation (Tab. V).

Finally, Table $\mathrm{V}$ reports the values of disutility associated with other events, such as complications (pulmonary embolism and deep vein thrombosis) or adverse events (infections during plasmapheresis and treatment-related severe bleeding), which may occur during an acute episode of iTTP, and those of utility, associated with non-fatal infarction and stroke in the acute and chronic phase $(25,32-34)$.

\section{Resources consumed and unit costs}

In the basic case, a cost of $€ 3,867.86$ for a $10 \mathrm{mg}$ vial of caplacizumab was considered. This cost reflects the ex-factory price net of mandatory legal reductions and gross of further agreed discounts. Based on the dosage regimen $(10 \mathrm{mg} /$ day) and the duration of treatment adopted in the model (35 days) (17), the average cost of caplacizumab for an acute episode of iTTP was calculated.

Excluding the cost of caplacizumab, Table VI shows the total costs of managing the acute episode of iTTP for the two treatment groups. These costs were calculated by multiplying the average consumption of each healthcare resource by its unit cost. The average consumption of healthcare resources was calculated based on the indications of the HERCULES study $(17,35)$ and, when necessary, supplementing with the thrombotic thrombocytopenic purpura guidelines (16), while the unit costs were obtained from the available literature and, in the absence of the latter, from the reimbursement fees currently in force in Italy, as a proxy for hospital costs. Specifically, the days spent by the patient in intensive care were valued based on the results of a national study that estimated the costs of hospitalisation in intensive care (36), while the days spent by the patient in ordinary care were valued based on the indications of the report on hospitalisation activity (hospital discharge records [schede di dimissione ospedaliera - SDO]) 2018 (37) (Tab. VI). In this second case, the unit cost was estimated by dividing the total expenditure $(€ 20,452,619)$ associated with hospitalisations associated with diagnosis-related groups (DRG) 397 (coagulation disorders) by the related days of hospitalisation $(53,247)$, considering DRG 397 as a proxy for hospitalisation for an acute episode of iTTP.

Since there are no specific standard hospital costs, plasmapheresis was instead valued using the rate established for the provision of outpatient services identified by code 99.71 (therapeutic plasmapheresis) (38). The molecular and biochemical diagnosis of acquired thrombocytopenic purpura is performed by performing the ADAMTS13 test valued, in the absence of a standard cost, with a fee of $€ 78.90$ (code 90.72.F ADAMTS13 protease activity) (39). The haematology visit was valorised using the general visit fee as a proxy (code 89.7) (38).

The therapies with folic acid (in support of plasmapheresis) and immunosuppression with corticosteroids (methylprednisolone) were valued using the relative price to the public $(40,41)$. 
TABLE VI - Cost of management of the acute episode of iTTP

\begin{tabular}{|c|c|c|c|c|c|}
\hline \multirow[t]{2}{*}{ Resource used } & \multirow[t]{2}{*}{ Unit cost } & \multicolumn{2}{|c|}{$\begin{array}{c}\text { PEX and } \\
\text { immunosuppression }\end{array}$} & \multicolumn{2}{|c|}{$\begin{array}{l}\text { Caplacizumab + PEX and } \\
\text { immunosuppression }\end{array}$} \\
\hline & & Frequency & Total cost & Frequency & Total cost \\
\hline Intensive care (days) & $€ 1,108.00(36)$ & $2.7(16.33)$ & $€ 2,991.60$ & $1.34(16.33)$ & $€ 1,484.72$ \\
\hline Hospitalisation (days) & $€ 384.11(37)$ & $8.1(16.33)$ & $€ 3,111.29$ & $8.2(16.33)$ & $€ 3,149.70$ \\
\hline Daily plasmapheresis (days) & $€ 438.99(38)$ & $6.5(16.33)$ & $€ 2,853.44$ & $5.5(16.33)$ & $€ 2,414.45$ \\
\hline Additional plasmapheresis (days) & $€ 438.99(38)$ & $0.1(16.33)$ & $€ 43.90$ & $0.1(16.33)$ & $€ 43.90$ \\
\hline ADAMTS13 test & $€ 78.90$ (39) & $4.0^{*}$ & $€ 315.60$ & $4.0^{*}$ & $€ 315.60$ \\
\hline Haematology specialist visit & $€ 20.66(38)$ & $2.0^{*}$ & $€ 41.32$ & $2.0^{*}$ & $€ 41.32$ \\
\hline Treatment with folic acid $5 \mathrm{mg}$ daily during plasmapheresis & $€ 0.09(40)$ & $0.3(34)$ & $€ 0.03$ & $0.3(34)$ & $€ 0.02$ \\
\hline Immunosuppressive therapy & $€ 35.54(41)$ & $3.0(34)$ & $€ 106.62$ & $3.0(34)$ & $€ 106.62$ \\
\hline Total cost & & & $€ 9,463.79$ & & $€ 7,556.33$ \\
\hline
\end{tabular}

*The test is performed four times during the acute episode of iTTP. Two of the four tests are usually performed when the patient has already been discharged from the hospital, then they are performed during a specialist visit by the haematologist.

Since the adverse events associated with the acute episode of iTTP, as well as stroke and myocardial infarction in the acute phase, occur during hospitalisation, no cost was considered in the model because, in fact, it was already valued within the days spent in ordinary regimen and/or in intensive care.

The management cost of the remission phase (€49.77) is the same for both treatment groups and was considered constant over time. This cost, regardless of the state of health associated with the patient in the remission phase, involves the performance of the ADAMTS13 test and the haematological visit every 6 months. Considering the 3-month model cycle length, a frequency of 0.5 was considered for both performances.

\section{Sensitivity analysis}

In order to assess the robustness of the decision-making model in response to deviations that in reality could occur with respect to the basic values of the parameters used (as sample estimates), a deterministic sensitivity analysis (DSA), a probabilistic sensitivity analysis (PSA) and a scenario analysis were conducted. Specifically, with regard to the DSA (one-way sensitivity analysis), the following parameters were sequentially varied, using, when possible, the respective confidence interval or, alternatively, assuming a variation of $\pm 20 \%$ :

- patients with exacerbation - PEX and immunosuppression (95\% Cl: 26.0\%-47.3\%; Beta distribution);

- patients with exacerbation - caplacizumab + PEX and immunosuppression (95\% Cl: 0.9\%-9.9\%; Beta distribution);

- probability of death due to an episode of iTTP - PEX and immunosuppression (95\% Cl: 9.6\%-17.3\%; Beta distribution);

- cost of an acute episode of iTTP - PEX and immunosuppression (change $\pm 20 \%$ : $€ 9,463.79-€ 11,356.55$; Gamma distribution);
- cost of an acute iTTP episode - caplacizumab + PEX and immunosuppression (change $\pm 20 \%$ : €6,045.06 $€ 9,067.60$; Gamma distribution);

- cost of exacerbation without re-hospitalisation - PEX and immunosuppression (change $\pm 20 \%$ : $€ 5,212.01-$ $€ 7,818.02$; Gamma distribution);

- cost of exacerbation without re-hospitalisation - caplacizumab + PEX and immunosuppression (change $\pm 20 \%$ : $€ 3,832.59$ - $€ 5,748.89$; Gamma distribution);

- cost of exacerbation with re-hospitalisation - PEX and immunosuppression (change $\pm 20 \%$ : $€ 5,212.01-$ $€ 7,818.02$; Gamma distribution);

- cost of remission (3 months) - PEX and immunosuppression reaction (change $\pm 20 \%$ : $€ 36.23-€ 65.45$; Gamma distribution);

- cost of remission (3 months) - caplacizumab + PEX and immunosuppression (change $\pm 20 \%$ : $€ 36.23$ - €65.45; Gamma distribution);

- probability of stroke during an acute iTTP episode (excluding death) - RR HERCULES (95\% Cl: 0.50-0.91; Gamma distribution);

- probability of infarction during an acute ITTP episode (excluding death) - RR HERCULES (95\% Cl: 0.75-1.35; Gamma distribution).

In addition to these parameters, the impact of the change in the discount applied to benefits and costs was also evaluated; specifically, two alternative scenarios were evaluated for the basic case: in the first case no discount was applied $(0 \%)$, while, in the second case, benefits and costs were discounted by applying a $5 \%$ discount.

With regard to the PSA, however, 2,000 iterations of the model were performed, each time making the values of the parameters simultaneously and randomly vary according to the probability distributions assigned to them and recalculating the results. The PSA product was therefore presented in the forms of the acceptability surface of the ICER (costeffectiveness plane) and the acceptability curve of the ICER 
TABLE VII - Results of the incremental cost-effectiveness analysis

\begin{tabular}{lcc}
\hline Parameters & $\begin{array}{c}\text { Caplacizumab + PEX and } \\
\text { immunosuppression }\end{array}$ & $\begin{array}{c}\text { PEX and } \\
\text { immunosuppression }\end{array}$ \\
\hline Outcomes & & $\begin{array}{c}\text { Incremental } \\
\text { change }\end{array}$ \\
Life years (LY) & 24.53 & 21.26 \\
Quality Adjusted Life Years (QALY) & 22.01 & 18.96 \\
\hline Direct costs (€) & & $€ 0$ \\
Caplacizumab & $€ 139,540$ & $€ 15,924$ \\
ITTP Management & $€ 12,553$ & $€ 15,924$ \\
TOTAL direct costs & $€ 152,093$ & 3.06 \\
\hline Incremental cost-effectiveness ratio (ICER) & & $€ 139,540$ \\
ICER (Caplacizumab + PEX and immunosuppression vs & & $-€ 3,372$ \\
PEX and immunosuppression) (costs/LY) & & $€ 136,169$ \\
ICER (Caplacizumab + PEX and immunosuppression vs & & $€ 44, \mathbf{5 7 2}$ \\
PEX and immunosuppression) (costs/QALY) & & \\
\hline
\end{tabular}

(Cost-Effectiveness Acceptability Curve). The acceptability surface area of the ICER shows the dispersion of the 2,000 results of the iterations, each according to the respective incremental changes in benefit (QALY) and cost of caplacizumab in combination with PEX and immunosuppression compared to PEX and immunosuppression. The acceptability curve of the ICER, still based on the 2,000 iterations, indicates (as a percentage) the frequencies with which the ICER (ratio between the incremental variation of the cost and the incremental variation of the benefit of caplacizumab in combination with PEX and immunosuppression compared to PEX and immunosuppression) is less than a certain threshold value, or provides the probability that, for a given threshold value, the treatment is cost-effective.

Finally, given that the one considered in the base case may not reflect the current transfer price of caplacizumab since additional discounts may be applied to healthcare facilities, a scenario analysis was conducted to assess the impact of different discount percentages on the price of caplacizumab on the calculation of the ICER for QALY. Since no specific information is available, four alternative scenarios of additional discount $(15 \%, 20 \%, 25 \%$ or $30 \%)$ of the base price of caplacizumab were proposed, assuming that the actual transfer price of the latter could fall within this variation.

\section{Results}

\section{Incremental cost-effectiveness analysis}

Overall, compared to PEX and immunosuppression, treatment with caplacizumab in combination with PEX and immunosuppression would result in an increase in survival of 3.27 years and an increase in survival adjusted for QoL of 3.06 QALY. The addition of caplacizumab to PEX and immunosuppression would result in an increase in the costs of pharmacological treatment (€136,169), which, in part, would be compensated by the reduction in the costs of disease management $(-€ 3,372)$ and the improvement in life expectancy and/or QoL. These values would result in an incremental cost per year of life gained of $€ 41,653$ and an incremental cost per QALY earned of $€ 44,572$ (Tab. VII).

In Italy, there are no defined acceptability thresholds for orphan drugs to which the ICERs estimated here can relate. However, several Italian publications report as a plausible threshold of acceptability a value of $€ 60,000$ per QALY gained (42-44). Therefore, if we compare this threshold value with the ICER for QALY estimated here, it can be considered that caplacizumab, in addition to PEX and immunosuppression, is a cost-effective therapeutic option.

\section{Sensitivity analysis}

The results of the DSA show how the probability of death due to an acute episode of iTTP (PEX and immunosuppression), the probability of exacerbation (caplacizumab + PEX and immunosuppression), the probability of stroke during an acute episode of ITTP and the cost of an acute episode of ITTP (PEX and immunosuppression) constitute the main drivers of incremental CEA (Fig. 2). The tornado diagram shows the impact range determined by the main variables on the ICER of caplacizumab in combination with PEX and immunosuppression compared to PEX and immunosuppression (Fig. 2).

By applying a discount of $0 \%$ to benefits and costs, the model estimates an ICER for LY and one for QALY of $€ 21,962$ and $€ 23,924$, respectively. By applying a 5\% discount, on the other hand, the ICER for LY would be $€ 57,709$, while the one for QALY would be €61,194.

With regard to PSA, on the other hand, the acceptability surface of the ICER shows how the entire dispersion of the 2,000 iterations is enclosed in the first quadrant (Fig. 3). Again on the basis of the 2,000 iterations, Figure 4 (acceptability curve of the ICER of caplacizumab in combination with PEX and immunosuppression compared to PEX and immunosuppression) indicates that the probability that the ICER of caplacizumab - in combination with PEX and immunosuppression 


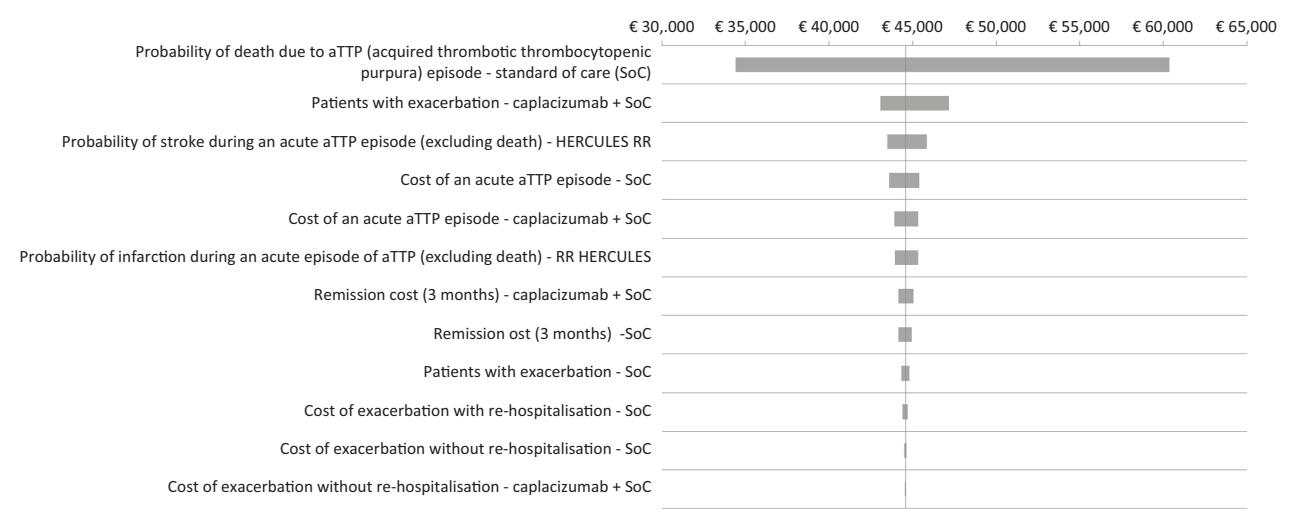

Fig. 2 - Tornado diagram: deterministic sensitivity analysis.

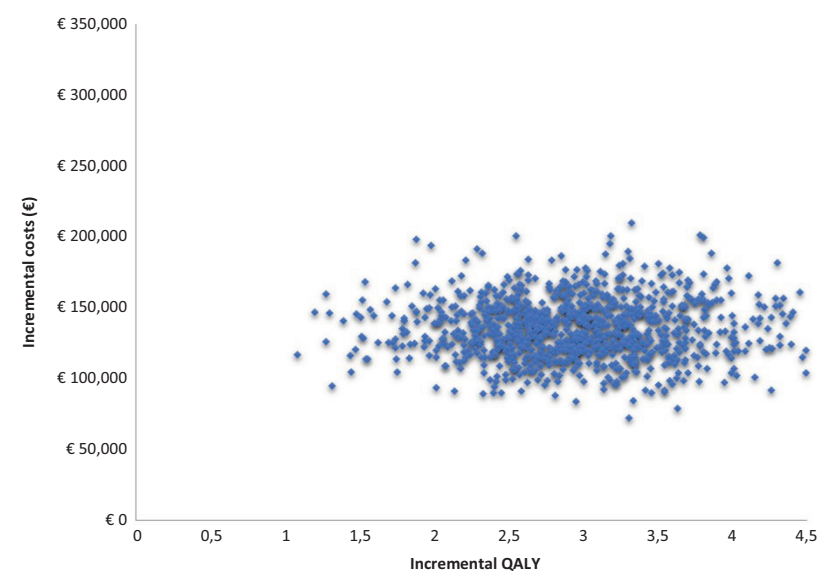

Fig. 3 - Acceptability surface area of the incremental cost-effectiveness ratio of caplacizumab in combination with plasma exchange (PEX) and immunosuppression compared to PEX and immunosuppression.

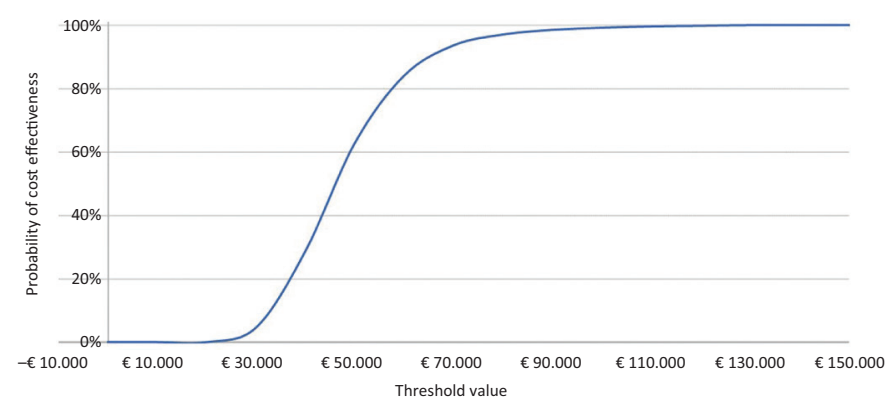

Fig. 4 - Acceptability curve of the incremental cost-effectiveness ratio of caplacizumab in combination with plasma exchange (PEX) and immunosuppression compared to PEX and immunosuppression.

compared to PEX and immunosuppression - is less than a threshold value of $€ 60,000$ would be $84.2 \%$.

Figure 5 and Table VII show the results of the scenario analysis. With a further discount of $15 \%$ of the price of caplacizumab, the probability that the ICER for QALY of caplacizumab in combination with PEX and immunosuppression compared to PEX and immunosuppression is less than a

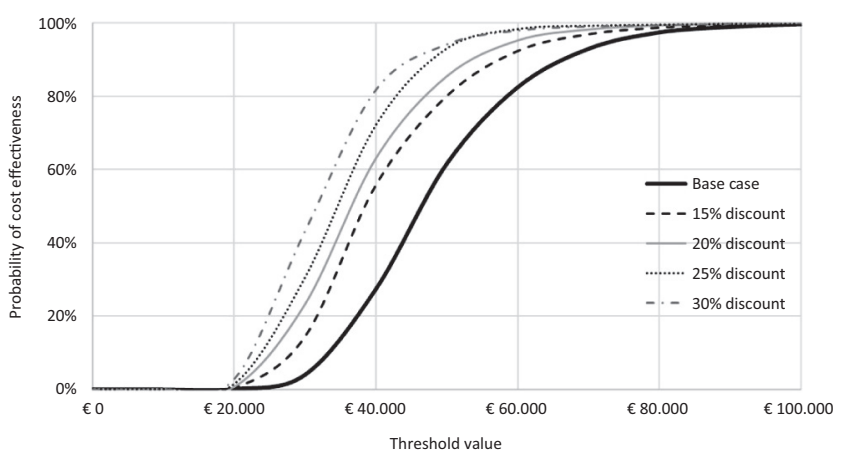

Fig. 5 - Scenario analysis: acceptability curve of the incremental cost-effectiveness ratio of caplacizumab in combination with plasma exchange (PEX) and immunosuppression compared to PEX and immunosuppression.

threshold value of $€ 60,000$ would be $92.8 \%$. This probability would rise to $95.3 \%, 96.9 \%$ and $98.2 \%$ compared to a corresponding discount of $20 \%, 25 \%$ or $30 \%$ (Fig. 5). By virtue of the different discount levels hypothesised, the ICER for QALY of caplacizumab in combination with PEX and immunosuppression compared to PEX and immunosuppression would decrease by up to $€ 30,869$ (Tab. VIII).

\section{Discussion and conclusions}

The availability of caplacizumab in addition to PEX and immunosuppression allows treated patients to achieve a faster resolution of the acute episode of iTTP compared to those treated with PEX and immunosuppression (17-19).

TABLE VIII - Results of the scenario analysis

\begin{tabular}{lcc}
\hline Parameters & ICER for QALY & $\Delta$ vs base case \\
\hline Base case & $€ 44,572$ & \\
Discount scenario 15\% & $€ 37,721$ & $-€ 6,851$ \\
Discount scenario 20\% & $€ 35,437$ & $-€ 9,135$ \\
Discount scenario 25\% & $€ 33,153$ & $-€ 11,419$ \\
Discount scenario 30\% & $€ 30,869$ & $-€ 14,419$ \\
\hline
\end{tabular}

ICER = incremental cost-effectiveness ratio; QALY = quality-adjusted life years. 
In view of this clinical advantage, the addition of caplacizumab to PEX and immunosuppression, however, raises the aspect of the sustainability of the related treatment cost to the SSN (servizio sanitario nazionale [national healthcare service]), which leads to the need to assess its acceptability through CEA. The need, therefore, to evaluate a new treatment over a time horizon suitable to collect the main benefits and costs results in an opportunity to perfect the economic analysis by extending it over a lifetime period, which, in turn, is abated, however, with the short duration of clinical studies. This justified, in this context, the use of a Markov model that, thanks to a simple representation of the clinical pathway of the patient with an acute episode of ITTP, made it possible to evaluate, over a lifetime period, the ICER of caplacizumab in addition to PEX and immunosuppression compared to PEX and immunosuppression.

As occurs whenever a decision-making model is used, the results of the analysis remain linked to certain areas of uncertainty. In this study, this uncertainty has several reasons, first and foremost the fact that not all efficacy comparisons between the two treatment regimens are related to a single study. The efficacy data of caplacizumab in combination with PEX and immunosuppression compared to PEX and immunosuppression are, in fact, extrapolated from the HERCULES study (17) and from a systematic review of the literature (25). In partial justification of the above, it should be noted that the use of different bibliographic sources represents a necessary 'evil' for the population of a decision-making model, particularly over a lifetime time horizon. A second aspect concerns the utility coefficients in question. In the model, not having any data, in order to estimate the disutility values associated with the manifestation of the acute episode of iTTP, the literature for sickle cell disease has been used, considering the impact on the QoL of the latter similar to that of iTTP due to frequent hospitalisations in the acute phase. A third aspect concerns the assumption that a previous acute episode of iTTP does not lead to differences in terms of effectiveness and costs compared to a first episode. A fourth aspect is, on the other hand, related to the assumption that, for both cohorts, in the acute phase, the occurrence of an event such as a heart attack or stroke does not lead to the intra-hospital death of the patient, not fully reflecting what could happen in clinical practice. Given that the probability of stroke or infarction is slightly lower for the group of patients treated with caplacizumab, it is believed that any such bias cannot significantly influence the outcome of the base case. Finally, the last aspect is the use, in some cases, of a proxy for the enhancement of healthcare consumption, as occurred, for example, for the haematological visit or for hospitalisation days.

In order to eliminate any uncertainty linked to the parameters adopted and the assumptions made, a DSA and PSA were conducted which, overall, confirmed the robustness of the results of the base case. In particular, the DSA showed that the probability of death for an acute episode of iTTP associated with the group treated with PEX and immunosuppression is the main driver of the incremental CEA, while the acceptability curve of the ICER for QALY, derived from PSA, showed a probability of $84.2 \%$ that caplacizumab in addition to PEX and immunosuppression is cost-effective compared to PEX and immunosuppression, against an accepted threshold of $€ 60,000$ (42-44).

It would also be good practice to discuss the results of a study by comparing them with those already published. Unfortunately, at the time of drafting this manuscript, no pharmacoeconomic evaluations of caplacizumab are present in the literature on the treatment of an acute episode of ITTP to be used for this purpose.

In light of what is reported here, we believe it is possible to state that the addition of caplacizumab to PEX and immunosuppression is a valid alternative to the treatment options currently available for the management of an acute episode of iTTP, an addition that would allow the hospital to achieve greater efficiency of the disease burden.

\section{Disclosures}

Conflict of interest: The authors declare no conflict of interest. Financial support: This research was made possible thanks to Sanofi Genzyme.

\section{References}

1. Osservatorio Malattie Rare (OMAR). Online (accessed December 2019).

2. Taruscio D. $17 / 8$ - II Registro Nazionale Malattie Rare nel contesto nazionale e internazionale. $3^{\circ}$ Rapporto (dati al 31 dicembre 2014). 2017. Online (accessed December 2019).

3. Scully M, Yarranton $\mathrm{H}$, Liesner R, et al. Regional UK TTP registry: correlation with laboratory ADAMTS 13 analysis and clinical features. Br J Haematol. 2008;142(5):819-826. CrossRef PubMed

4. Joly BS, Coppo P, Veyradier A. Thrombotic thrombocytopenic purpura. Blood. 2017;129(21):2836-2846. CrossRef PubMed

5. Sadler JE. What's new in the diagnosis and pathophysiology of thrombotic thrombocytopenic purpura. Hematology (Am Soc He-matol Educ Program). 2015;2015(1):631-636. CrossRef PubMed

6. Callewaert F, Roodt J, Ulrichts $\mathrm{H}$, et al. Evaluation of efficacy and safety of the anti-VWF Nanobody ALX-0681 in a preclinical baboon model of acquired thrombotic thrombocytopenic purpura. Blood. 2012;120(17):3603-3610. CrossRef PubMed

7. Terrell DR, Williams LA, Vesely SK, Lammle B, Hovinga JA, George JN. The incidence of thrombotic thrombocytopenic purpura-hemolytic uremic syndrome: all patients, idiopathic patients, and patients with severe ADAMTS-13 deficiency. J Thromb Haemost. 2005;3(7):1432-1436. CrossRef PubMed

8. Kremer Hovinga JA, Coppo P, Lammle B, Moake JL, Miyata T, Vanhoorelbeke K. Thrombotic thrombocytopenic purpura. Nat Rev Dis Primers. 2017;3(1):17020. CrossRef PubMed

9. Bennett $\mathrm{CL}$, Djulbegovic B. Thrombotic thrombocytopenic purpura: gaining knowledge. Lancet Haematol. 2016;3(5): e210-e211. CrossRef PubMed

10. Falter T, Alber KJ, Scharrer I. Long term outcome and sequelae in patients after acute thrombotic thrombocytopenic purpura episodes. Hamostaseologie. 2013;33(2):113-120. CrossRef PubMed

11. Reese JA, Muthurajah DS, Kremer Hovinga JA, Vesely SK, Terrell DR, George JN. Children and adults with thrombotic thrombocytopenic purpura associated with severe, acquired Adamts13 deficiency: comparison of incidence, demographic and clinical features. Pediatr Blood Cancer. 2013;60(10):1676-1682. CrossRef PubMed 
12. Miller DP, Kaye JA, Shea K, et al. Incidence of thrombotic thrombocytopenic purpura/hemolytic uremic syndrome. Epidemiology. 2004;15(2):208-215. CrossRef PubMed

13. Knoebl P, Cataland S, Peyvandi F, et al. Efficacy and safety of open-label caplacizumab in patients with exacerbations of acquired thrombotic thrombocytopenic purpura in the HERCULES study. J Thromb Haemost. 2020;18(2):479-484. CrossRef PubMed

14. Riva S, Mancini L, Maino A, et al. Long-term neuropsychological sequelae, emotional wellbeing and quality of life in patients with acquired thrombotic thrombocytopenic purpura. Haematologica. 2020;105(7):1957-1962. CrossRef PubMed

15. Kennedy AS, Lewis QF, Scott JG, et al. Cognitive deficits after recovery from thrombotic thrombocytopenic purpura. Transfusion. 2009;49(6):1092-1101. CrossRef PubMed

16. Scully M, Hunt BJ, Benjamin S, et al; British Committee for Standards in Haematology. Guidelines on the diagnosis and management of thrombotic thrombocytopenic purpura and other thrombotic microangiopathies. Br J Haematol. 2012; 158(3):323-335. CrossRef PubMed

17. Scully M, Cataland SR, Peyvandi F, et al; HERCULES Investigators. Caplacizumab treatment for acquired thrombotic thrombocytopenic purpura. N Engl J Med. 2019;380(4):335-346. CrossRef PubMed

18. Peyvandi F, Scully M, Kremer Hovinga JA, et al; TITAN Investigators. Caplacizumab for acquired thrombotic thrombocytopenic purpura. N Engl J Med. 2016;374(6):511-522. CrossRef PubMed

19. Peyvandi F, Cataland SR, Scully M, et al. Integrated efficacy results from the phase II and phase III studies with caplacizumab in patients with acquired thrombotic thrombocytopenic purpura. Blood. 2018;132(Suppl. 1):373. CrossRef

20. Area Strategia ed Economia del Farmaco. Settore HTA ed Economia del Farmaco. Elenco dei farmaci innovativi ai sensi dell'articolo 10 , comma 2, legge 8 novembre 2012, n. 189, come definito dall'art. 1 comma 1 e 2 dell'accordo Stato-Regioni del 18 novembre 2010 (Rep. Atti n. 197/CSR). Disponibile su: Online (accessed August 2020).

21. Sonnenberg FA, Beck JR. Markov models in medical decision making: a practical guide. Med Decis Making. 1993;13(4): 322-338. CrossRef PubMed

22. Fattore G. Proposta di Linee Guida per la valutazione economica degli interventi sanitari in Italia. Pharmacoeconomics -Ital-Res-Articles 2009;11(2):83-93. CrossRef

23. Lotta LA, Mariani M, Consonni D, et al. Different clinical severity of first episodes and recurrences of thrombotic thrombocytopenic purpura. Br J Haematol. 2010;151(5):488-494. CrossRef PubMed

24. Caro JJ, Briggs AH, Siebert U, Kuntz KM; ISPOR-SMDM Modeling Good Research Practices Task Force. Modeling good research practices - overview: a report of the ISPOR-SMDM Modeling Good Research Practices Task Force - 1. Value Health. 2012;15(6):796-803. CrossRef PubMed

25. Ablynx Data on file. Systematic review on the clinical burden of disease in thrombotic thrombocytopenic purpura. 2017.
26. Team RC. A language and environment for statistical computing. R Foundation for Statistical Computing; 2018. Online

27. ISTAT. Istituto nazionale di statistica. Tavole di mortalità della popolazione residente: Italia, anno 2017. Online

28. Yusuf S, Pitt B, Davis CE, Hood WB Jr, Cohn JN; SOLVD Investigators. Effect of enalapril on mortality and the development of heart failure in asymptomatic patients with reduced left ventricular ejection fractions. N Engl J Med. 1992;327(10): 685-691. CrossRef PubMed

29. Rutten-Jacobs LCA, Arntz RM, Maaijwee NA, et al. Long-term mortality after stroke among adults aged 18 to 50 years. JAMA. 2013;309(11):1136-1144. CrossRef PubMed

30. Scalone L, Cortesi PA, Ciampichini R, Cesana G, Mantovani LG. Health Related Quality of Life norm data of the general population in Italy: results using the EQ-5D-3L and EQ-5D-5L instruments. Online

31. Anie KA, Grocott H, White L, Dzingina M, Rogers G, Cho G. Patient self-assessment of hospital pain, mood and health related quality of life in adults with sickle cell disease. BMJ Open. 2012;2(4):e001274. CrossRef

32. NICE Clinical Guideline Centre. Lipid modification: cardiovascular risk assessment and the modification of blood lipids for the primary and secondary prevention of cardiovascular disease. Clinical Guideline CD181 Appendices. July 2014. Online

33. NICE. NICE TA327. Dabigatran etexilate for the treatment and secondary prevention of deep vein thrombosis and/or pulmonary embolism. Online

34. NICE. NICE TA420. Ticagrelor for preventing atherothrombotic events after myocardial infarction. Online

35. Sanofi Data on file. Clinical Study Report HERCULES Study.

36. Pradelli L, Klek S, Mayer K, et al. Omega-3 fatty acid-containing parenteral nutrition in ICU patients: systematic review with meta-analysis and cost-effectiveness analysis. Crit Care. 2020; 24(1):634. CrossRef PubMed

37. Rapporto sull'attività di ricovero ospedaliero SDO 2018. Online (accessed January 2018).

38. Prestazioni di assistenza specialistica ambulatoriale. Online

39. Tariffario Regione Veneto 2017. Online

40. Farmadati 2019. Acido Folico (DOC Generici), $5 \mathrm{mg}, 120$ CPR Prezzo ex factory al lordo delle riduzioni di legge $€ 11,25$.

41. Lista farmaci classe A 15-11-19 (ITALIA)SOLUMEDROL, 1 flacone IM EV $1 \mathrm{~g}+1$ flacone solv $16 \mathrm{ml}$. Online

42. Martone N, Lucioni C, Mazzi S. V. Fadda - Valutazione di costo-efficacia dei nuovi farmaci oncologici immessi sul mercato italiano - Global \& Regional Health Technol Assess 2014;1(2): 31-43. CrossRef

43. Messori A, Santarlasci B, Trippoli S, Vaiani M. Controvalore economico del farmaco e beneficio clinico: stato dell'arte della metodologia e applicazione di un algoritmo farmacoeconom-ico. Pharmacoeconomics - Ital-Res-Articles. 2003;5(2): 53-67. CrossRef

44. Messori A, Maratea D, Nozzoli C, Bosi A. The role of bortezomib, thalidomide and lenalidomide in the management of multiple myeloma: an overview of clinical and economic information. Pharmacoeconomics. 2011;29(4):269-285. CrossRef PubMed 